\title{
Variation in the origin of the posterior cerebral artery in adult Sri Lankans
}

\author{
K. R. D. De Silva ${ }^{1}$, T. R. N. Silva ${ }^{1}$, W. S. L. Gunasekera², R. W. Jayesekera ${ }^{3}$ \\ ${ }^{1}$ Department of Anatomy, Faculty of Medical Sciences, University of Sri Jayerwardenepura, Nugegoda, ${ }^{2}$ National Hospital of \\ Sri Lanka, Colombo, ${ }^{3}$ Department of Anatomy, Faculty of Medicine, University of Colombo, Sri Lanka
}

\begin{abstract}
Background: The degree of contribution from the vertebro-basilar and carotid systems to the origin of the posterior cerebral artery (PCA) is of clinico-anatomical importance. Three configurations in the bifurcation of the posterior communicating artery (PcomA) have been described, foetal, transitional and adult. Objective: To examine the extent of contribution from the vertebro-basilar and carotid systems to the origin of the PCA in adult autopsy brains in subjects who had died of causes unrelated to the brain. Materials and Methods: The external diameter of the PcomA, pre communicating part (P1) and the post communicating part (P2) of PCA in 225 normal Sri Lankan adult cadaver brains was measured using a calibrated grid. Results: The adult configuration was present in 220 (93.3\%); (bilaterally in 200 (88.8\%), and unilaterally in 20 (8.8\%) ten on each side. Foetal configuration was seen in $17(4.4 \%)$; bilaterally in $3(1.3 \%)$, and unilaterally in 14 $(6 \%) 8$ on the left and 6 on the right. Transitional configuration was seen in $8(2.2 \%)$; bilaterally in $2(0.9 \%)$, and unilaterally in $6(2.5 \%) 2$ on the left and 4 on the right. Conclusion: This study reveals that the internal carotid artery (ICA) provided the major supply to the PCA in $4.4 \%$ of foetal and $2.2 \%$ of transitional configurations. The adult configuration was present in 220 (93.3\%), the highest recorded in the literature. This finding may be of relevance to vertebrobasilar ischaemia and infarcts in the territory of the PCA.
\end{abstract}

Address for correspondence: Dr. K. R. D. De Silva, Department of Anatomy, Faculty of Medical Sciences, University of Sri J ayew ardenepura, Nugegoda. E-mail: ranilds@ sltnet.lk

DOI: $10.4103 / 0028-3886.48821$
Key words: Circle of Willis, configuration, posterior cerebral artery, vertebrobasilar

\section{Introduction}

The posterior cerebral artery (PCA) is divided into two parts by the posterior communicating artery (PcomA), the proximal part is named as the pre communicating part (P1) and the distal part as the post communicating part (P2), three basic configurations of the PcomA has been described ${ }^{[1]}$ foetal, transitional and adult. In the foetal configuration: the diameter of the ipsilateral pre communicating (P1) segment of PCA is less than the diameter of PcomA, so that the blood supply to the occipital lobe is mainly via the internal carotid arteries (ICA). In transitional configuration the PcomA is equal in diameter to the P1 segment of the PCA. In the adult configuration $\mathrm{P} 1$ has a diameter larger than the PcomA (P1 > PcomA) so that the blood supply to the occipital lobe is mainly via the vertebrobasilar system. Such anatomical variations may have clinical significance as it makes it possible for thrombotic material arising in atherosclerotic lesions in the ICA to be dislodged into the PCA via the larger diameter PcomA. Also, extensive variations between the territories of vascular distribution of middle cerebral artery (MCA) and PCA have been reported. ${ }^{[2]}$ As such, cerebral infarction due to PCA occlusion could sometimes simulate MCA territory infarction with acute hemiparesis, hemisensory loss, hemianopia, visuospatial neglect, and aphasia which are more common in occlusion of the MCA. The MCA almost always arises from the internal carotid arteries, but in about $10-40 \%,{ }^{[1,3-11]}$ the ICA is responsible for the majority of blood flow in the PCA as well. The anatomical configuration of the PcomA has not been studied in the Sri Lankan populations and the purpose of this study is to examine the degree of contribution from the vertebrobasilar and carotid systems to the origin of the PCA in adult autopsy brains in subjects 
who have died of causes unrelated to the brain.

\section{Materials and Methods}

Two hundred and twenty five postmortem brains were obtained during judicial autopsies in individuals aged between 18 and 73 years who had died of causes unrelated to the brain, and whose brains demonstrated no gross macroscopic evidence of cerebrovascular disease. The brains were removed from the cranial cavity and fixed in 10\% formaldehyde. The arteries comprising the circle of Willis (CW) together with the basilar artery and the minute branches arising from the main vessels were carefully removed from the base of the brain. Blood was carefully washed out from the arteries with isotonic saline. The external diameters of PcomA communicating arteries, P1 and P2 were measured using a stereomicroscope equipped with a micrometer calibrator (Leica). The equipment was standardised according to the manufacturer's specifications. The measurements were performed three times on each segment, by the first author and the average diameter was recorded. Line diagrams and photographic records were made and the origin of PCA ascertained. A vessel was considered as absent when it was not detected under the dissecting microscope.

\section{Results}

The variations in the configuration observed in adult brains are given in Table 1. The adult configuration was present in 220 (93.3\%); bilaterally in 200 (88.8\%), and unilaterally in 20 (8.8\%) ten being on the left side and ten on the right side. Foetal configuration was seen in 17 (4.4\%); bilaterally in $3(1.3 \%)$, and unilaterally in $14(6 \%) 8$ on the left and 6 on the right. Transitional configuration was seen in $8(2.2 \%)$; bilaterally in $2(0.9 \%)$, and unilaterally in $6(2.5 \%) 2$ on the left and 4 on the right [Figures 1-6].
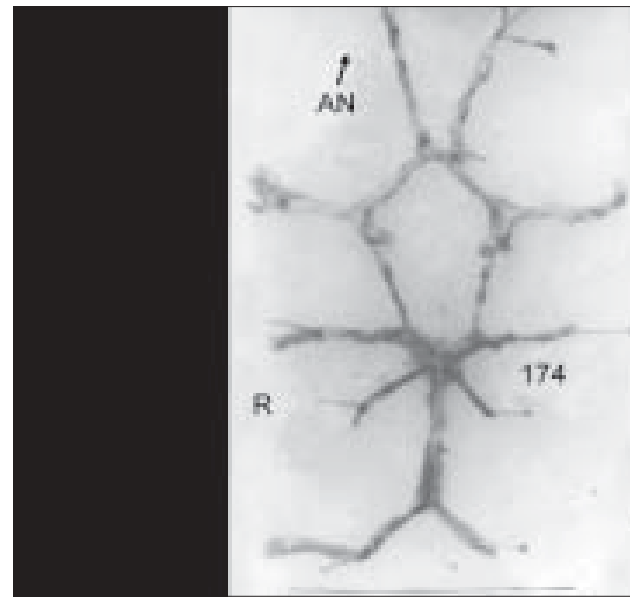

Figure 1: Adult configuration

\section{Discussion}

Foetal configuration, where PCA arose predominantly from the ICA was seen in $4.4 \%$ in the present study as compared to $15 \%$ to $40 \%$ reported in previous studies..$^{[1,3,5-6,8,11]}$ A possible reason for the wide range in the foetal configuration reported in several previous studies may be the diversity in nomenclature and many have relied upon rough estimations of the vessel diameter, rather than actual measurements in determining the configurations. Accurate measurement of the actual external diameter of all the component vessels of the CW has previously been done in India ${ }^{[5]}$ and Netherlands, ${ }^{[6]}$ [Table 2] shows the distribution of the configurations of the PcomA in different studies ${ }^{[5,6]}$ compared with the present study.

The incidence of the adult configuration was highest in the present study when compared to the rest. This finding may be of significance in relation to the occurrence of posterior territory ischaemia as it is known that the incidence of intracranial atherosclerosis

\begin{tabular}{lcc}
\hline \multicolumn{3}{l}{ Table 1: Variations in the configurations of adult brains } \\
\hline Configuration & \multicolumn{2}{c}{ Adult brains $\mathrm{N}=225$} \\
\cline { 2 - 3 } & Number & $\%$ \\
\hline Adult configuration & & \\
$\quad$ Bilateral & 200 & 88.8 \\
$\quad$ Left & 10 & 4.4 \\
$\quad$ Right & 10 & 4.4 \\
Total & 220 & 93.3 \\
Fetal configuration & & \\
$\quad$ Bilateral & 3 & 1.3 \\
$\quad$ Left & 8 & 3.5 \\
$\quad$ Right & 6 & 2.6 \\
Total & 17 & 4.4 \\
Transitional configuration & & \\
$\quad$ Bilateral & 2 & 0.88 \\
$\quad$ Left & 2 & 0.88 \\
$\quad$ Right & 4 & 1.7 \\
Total & 8 & 2.2 \\
\hline
\end{tabular}

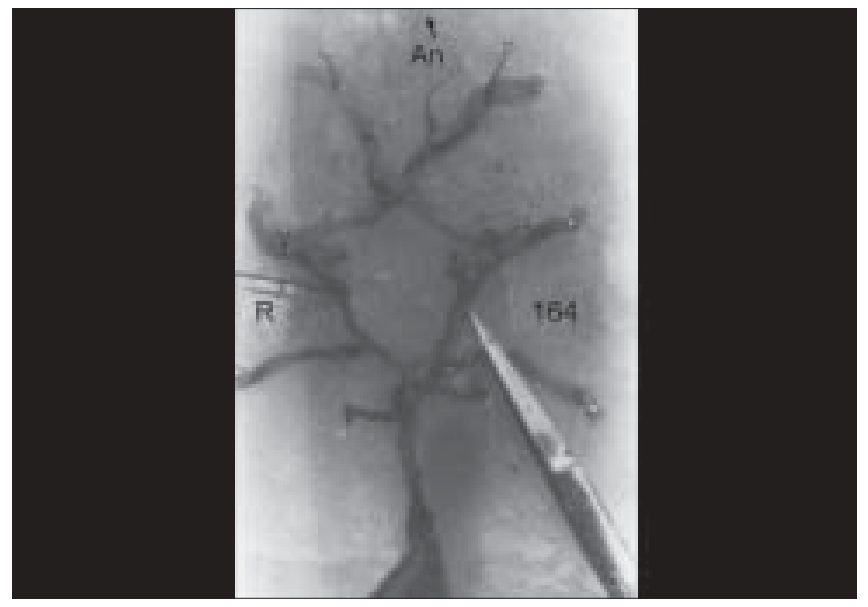

Figure 2: Bilateral fetal configuration 


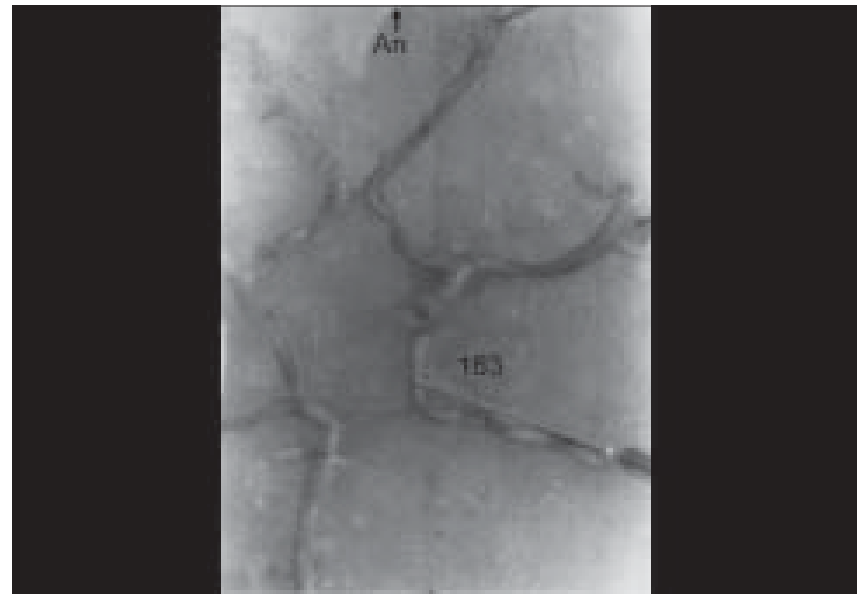

Figure 3: Left side fetal and right side adult configuration

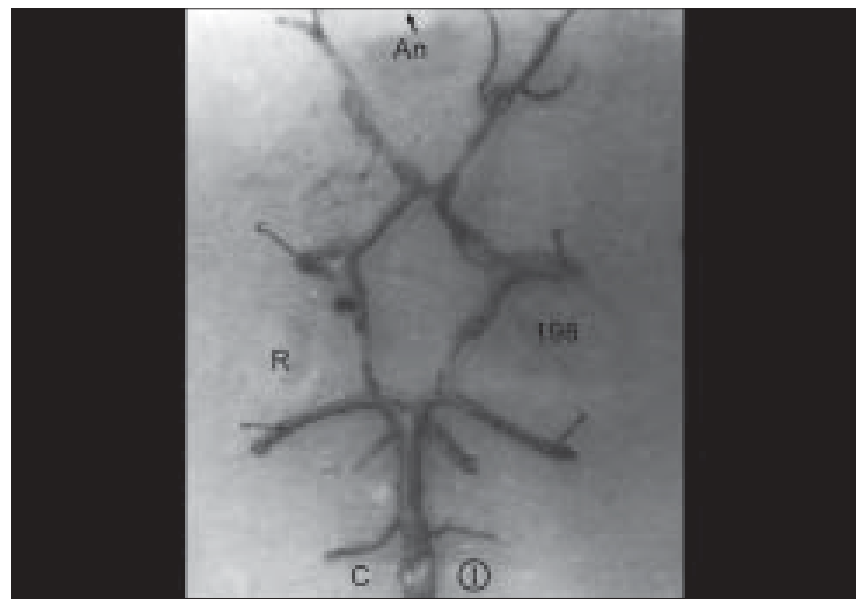

Figure 5: Right side transitional and left side adult configuration

in anterior circulation stroke is much higher in Asians than Caucasians. ${ }^{[12]}$ Posterior circulation stroke (PCS) was reported in $26.7 \%$ of all ischemic strokes in the Lausanne Stroke Registry ${ }^{[13]}$ and in $26 \%$ in the BesanCon Stroke Registry. ${ }^{[14]}$ This is in contrast to the relatively high prevalence of $39.8 \%$ PCS reported among Asians in the Hallym Stroke Registry, Korea. ${ }^{[15]}$ Infarcts in the territory of the posterior cerebral arteries (PCAs) account for only $5-10 \%$ of all strokes. ${ }^{[13,16,17]}$

\section{Conclusions}

The present study reveals that the degree of contribution from the ICA to the origin of the PCA is $4.4 \%$ of foetal and $2.2 \%$ of transitional configurations, whereas adult configuration was present in 220 (93.3\%), the highest recorded in the literature. This may be due to haemodynamic, vasomotor, genetic, environmental, geographical and embryological factors, or a combination of these and may be of relevance to vertebrobasilar ischaemia and infarcts in the territory of the PCA and warrants further investigation.

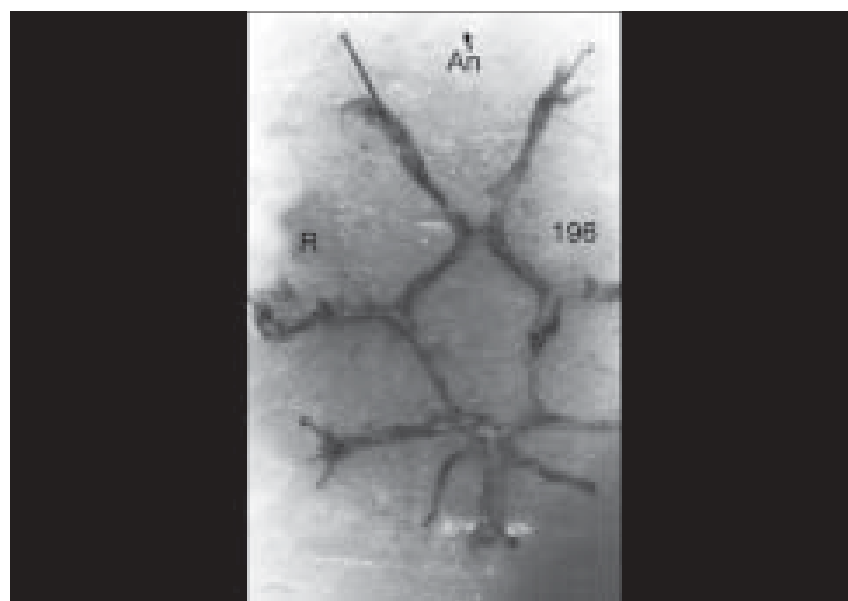

Figure 4: Bilateral transitional configuration

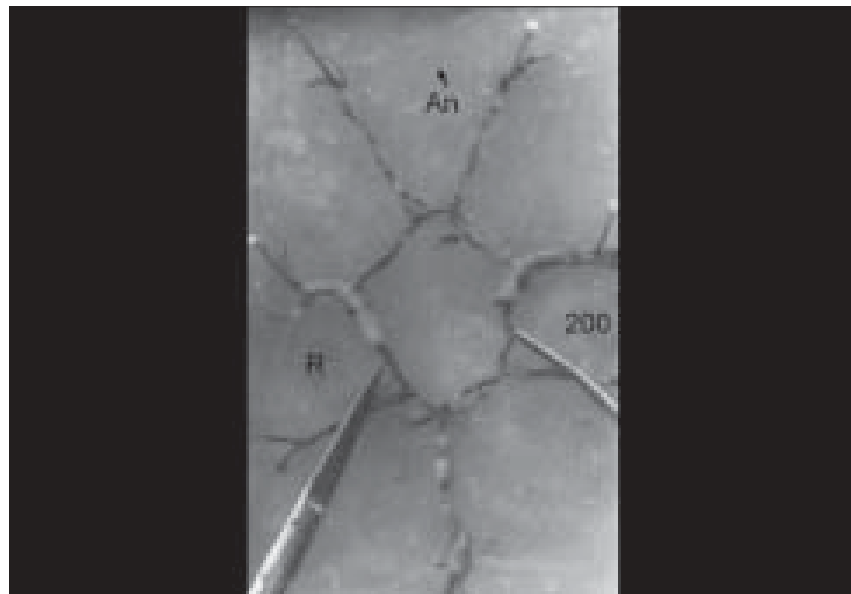

Figure 6: Right side transitional and left side foetal configuration

Table 2: Comparison of the variations in configuration in adult brains with other studies in the literature

\begin{tabular}{lccc}
\hline Name of study & Present & Kamath $^{[10]}$ & Overbeeke $^{[11]}$ \\
\hline Country & Sri Lanka & India & Netherlands \\
Total brains & 225 & 100 & 100 \\
Adult configuration (\%) & 93.3 & 73.5 & 84 \\
Fetal configuration (\%) & 4.4 & 25 & 14 \\
Transitional configuration (\%) & 2.2 & 1.5 & 2 \\
\hline
\end{tabular}

\section{Acknowledgment}

This study was supported by Hiran Tillekeratne Research Fund, University Grants Commission and Research Grant from the University of Sri Jayewadenepura. We wish to thank Dr. L. B. L. De Alwis and Dr. Ananda Samarasekera, Judicial Medical Officers, for granting permission to inspect the samples, Mr. A. Dais for photography, Mr. R. A. D. Ratuwithana for data entry.

\section{References}

1. Saeki N, Rhoton AL Jr. Microsurgical anatomy of the upper basilar artery and the posterior circle of Willis. J Neurosurg 1977;46:563-78. 
2. van der Zwan A, Hillen B, Tulleken CA, Dujovny M, Dragovic L. Variability of the territories of the major cerebral arteries. J Neurosurg 1992;77:927-40.

3. Fujimoto K, Tanaka O. Morphological examination of the circulus arteriosus cerebri humani (circle of Willis) I: Anterior and posterior communicating arteries. Kaibogaku Zasshi 1989;64:481-9.

4. Jongen JC, Franke CL, Soeterboek AA, Versteege CW, Ramos LM, van Gijn J. Blood supply of the posterior cerebral artery by the carotid system on angiograms. J Neurol 2002;249:455-60.

5. Kamath S. Observations on the length and diameter of vessels forming the circle of Willis. J Anat 1981;133:419-23.

6. Van Overbeeke JJ, Hillen B, Tulleken CA. A Comparative study of the circle of Willis in fetal and adult life: The configuration of the posterior bifurcation of the posterior communicating artery. J Anat 1991;176:45-54.

7. Pedroza A, Dujovny M, Artero JC, Umansky F, Berman SK, Diaz FG, et al. Microanatomy of the posterior communicating artery. Neurosurgery 1987;20:228-35.

8. Riggs HE, Rupp C. Variation in form of the circle of Willis. The relation of the variations to collateral circulation: Anatomic analysis. Arch neuro 1963;8:8-14.

9. Tulleken CA, Luiten ML. The basilar artery bifurcation: Microscopical anatomy. Acta Neurochir (Wien) 1987;85:50-5.

10. Zeal AA, Rhoton AL Jr. Microsurgical anatomy of the posterior cerebral artery. J Neurosurg 1978;48:534-59.
11. Alpers BJ, Berry RG, Paddison RM. Anatomical studies of the circle of Willis in normal brain. Arch Neurol Psychiatry 1959;8I:409-18.

12. Moossy J. Pathology of cerebral atherosclerosis. Influence of age, race, and gender. Stroke 1993;24:I22-3; I31-2.

13. Bogousslavsky J, Melle GV, Regli F. The Lausanne stroke registry: Analysis of 1000 consecutive patients with first stroke. Stroke 1988;19:1083-92.

14. Moulin T, Tatu L, Crépin-Leblond T, Chavot D, Bergès S, Rumbach T. The BesanÇon stroke registry: An acute stroke registry of 2500 consecutive patients. Eur Neurol 1997;38:10-20.

15. Lee Jh, Han SJ, Yun YH, Jung S, Cho SJ, Yu KH, et al. Posterior circulation ischemic stroke in Korean population. Eur J Neurol 2006;13:742-8.

16. Kinkel WR, Newman RP, Jacobs L. Posterior cerebral artery branch occlusions: CT and anatomic considerations. In: Berguer R, Bauer RB, editors. Vertebrobasilar arterial occlusive disease. New York: Raven Press; 1984. p. 117-33.

17. Kleihues P, Hizawa K. Die Infarkte der A. cerebri posterior: Pathogenese und topographische Beziehungen zur Sehrinde. Arch Psychiatr Nervenkr 1966;208:263-84.

Accepted on 26-01-2009

Source of Support: Hiran Tillekeratne Research Fund, University

Grants Commission and Research Grant from the University of

Sri Jayewadenepura, Conflict of Interest: None declared. 